5. Wollin, G., Ericson, D. B., Ryan, W. B. F. \& Foster, J. H. Earth planet. Sci. Lett. 12, 175-183 (1971).

6. Ninkovich, D., Opdyke, N. D., Heezen, B. C. \& Foster, J. H. Earth planet. Sci. Lett. 1, 476-492 (1966).

7. Denham, C. R. \& Cox, A. Earth planet. Sci. Lett. 13, 81-190 (1971)

8. Liddicoat, J. C. \& Coe, R. S. J. geophys. Res. 84, 261-271 (1979).

9. Mankinen, E. A. Donnelly, J. M. \& Grommé, C. S. Geology 6, 653-656 (1978)

10. Mankinen, E. A. \& Grommé, C. S. Geophys. Res. Lett. 9, 1279-1282 (1980).

11. Lowrie, W. \& Kent, D. V. Earth planet. Sci. Lett. (in the press

\section{Female choice in widowbirds}

FIELD studies of the long-tailed widowbird, Euplectes progne, by Andersson ${ }^{1}$ involved experimental manipulation of the tail-lengths of territorial males and measurement of their breeding success in terms of the number of females that nested in the male's territory. The Darwin-Fisher theory ${ }^{2,3}$ of the role of sexual selection in the evolution of bird plumage would predict that females should prefer to mate with males with longer tails. Although Andersson interprets his data as supporting this prediction, we feel that this may not be justified in view of the following oversights.

First, the number of new nests was not least for males with shortened tails as claimed, there being no difference between males with short tails and normal males (four new nests in each case). Second, Andersson claims ${ }^{1}$ that any tendency of females to mate in one territory but nest in another (which is known to occur in other polygynous birds ${ }^{4}$ ) would fail to produce a spurious bias in favour of the Darwin-Fisher theory. This claim is only justified, however, if the DarwinFisher theory is true and females prefer to mate with long-tailed males but nest in the territories of other males. If the theory is not true, and females mate randomly or with a preference for short-tailed males but nest in the territories of long-tailed males, such behaviour could produce a spurious bias in the results in favour of the theory.

Third, over the range of tail lengths that sexual selection would be assumed to have acted in the evolutionary past (that is, short to normal tail), there is no hint that females prefer longer tails (for example, no correlation between tail length and number of nests on the territory before treatment began; absolutely no difference between short-tailed and normal males; and a tendency to prefer normal-but-cut to normal males even though the tails of the former were on average $1 \mathrm{~cm}$ shorter).

Males with long tails did significantly better than normal males and males with shortened tails, but did not do significantly better than males with normal-but-cut tails. The proper conclusion from the data should therefore have been that females preferred to nest in the territories of males with $25 \mathrm{~cm}$ of feathers glued on to them, irrespective of the total tail length. Such a conclusion could be interpreted in terms of predation hypotheses for the evolution of bird coloration ${ }^{5}$.

We suggest the reason that female widowbirds prefer to nest in the territories of males with long feathers glued on to them, irrespective of total tail length, is that such males, through marginally more ponderous flight, are better decoys ${ }^{5}$ than normal or short-tailed males. Perhaps in a non-experimental context females choose to nest in the territories of males that happen to be good decoys through other non-genetic factors (for example, age, senility, damage). It does not follow, necessarily, that females also choose to mate with such males.

\section{R. ROBIN BAKER}

Department of Zoology,

University of Manchester,

Manchester M13 9PL, UK

\section{G. A. PARKER}

Department of Zoology,

University of Liverpool,

Liverpool L69 3BX, UK

1. Andersson, M. Nature 299, 818-820 (1982).

2. Darwin, C. The Descent of Man and Selection in Relation to Sex (Murray, London, 1871)

3. Fisher, R. A. The Genetical Theory of Natural Selection (Clarendon, Oxford, 1930)

4. Bray, O., Kennelly, J. \& Guarino, J. Wilson Bull. 87 , 187-195 (1975).

Baker, R. R. \& Parker, G. A. Phil. Trans. R. Soc. B287, 63-130 (1979).

ANDERSSON REPLIES-Baker and Parker question the assumption (supported in other Euplectes species) that females tend to nest on the territory of the male with which they mate. If females mate randomly or prefer short-tailed males, but nest in territories of elongated males, the result is not evidence for Darwin's hypothesis. However, there seems no plausible reason to expect such a peculiar difference in female choice of nest site as opposed to mate.

In their other two points, Baker and Parker's criticism depends entirely on their unsupported assumption that the (small and nonsignificant; $P>0.6$ ) difference between control males I and II did not arise from chance variation, but because elongated and cut-and-restored males through 'marginally more ponderous flight' attracted more females to nest (but not mate) on their territories. However, there is no indication that cutand-restored males had more ponderous flight than the other control males. They showed almost identical changes in mean rates of flight display and attack after manipulation. Moreover, because feather vane was removed along the $1 \mathrm{~cm}$ joint to avoid vane overlap, the operation lightened each cut-and-restored feather by $\sim 0.5 \mathrm{mg}$, including glue. The two parts of the feather were carefully aligned, and two specialists on bird flight, Drs Ulla and
Åke Norberg, on inspection considered any noticeable effect on the bird's flight performance as highly unlikely. The two control groups should therefore represent one single category from an aerodynamic as well as from the females' point of view. Their difference of $1 \mathrm{~cm}$ compared with a total tail length of $\sim 50 \mathrm{~cm}$ would seem too small for females to notice; the difference to the other two groups was $\sim 25 \mathrm{~cm}$. It is therefore extremely unlikely that the cut-and-glue operation rather than changes in male tail length caused the significant trend in the result. Further, because cut-and-restored males were more successful than 'shortened' males, there is a hint that females preferred longer tails also within the normal range of lengths, contrary to the claim of Baker and Parker.

They favour their own predation hypothesis ${ }^{5}$, and suggest that females chose to nest on the territories of the best 'decoy' males, most likely to draw predators to themselves and hence to reduce the risk for female and young. But attraction of predators to the territory might just as well raise the risk also for the female and young. This alternative explanation therefore seems logically doubtful, in addition to being based on very unrealistic assumptions about differences between the control groups.

I therefore think it is most reasonable to interpret the trend of higher male success with increased tail length after manipulation as evidence that tail length influenced female choice as suggested by the Darwin-Fisher theory. However, further experiments are desirable in this or other species with similar ornaments and mating system, such as whydahs, peacocks and other pheasants.

I thank Frank Götmark and Åke Norberg for helpful comments.

\section{MALTE ANDERSSON}

Department of Zoology,

University of Gothenburg,

PO Box 25059

S-400 31 Gothenburg, Sweden

\section{Matters Arising}

Matters Arising is meant as a vehicle for comment and discussion about papers that appear in Nature. The originator of a Matters Arising contribution should initially send his manuscript to the author of the original paper and both parties should, wherever possible, agree on what is to be submitted. Neither contribution nor reply (if one is necessary) should be longer than 500 words and the briefest of replies, to the effect that a point is taken, should be considered. 